\title{
Distribution Coefficients of Polonium Between 0.75 M HDEHP in Cyclo- hexane and Aqueous Hydrochloric and Nitric Acids
}

\author{
Guogang Jia* and Giancarlo Torri
}

Agency for Environmental Protection and for Technical Services, Via V. Brancati 48, 00144 Roma, Italy

\begin{abstract}
The distribution coefficients (D) of polonium between $0.75 \mathrm{M}$ di(2-ethyhexyl)phosphoric acid (HDEHP) in cyclohexane and aqueous hydrochloric and nitric acids have been studied. Results indicate that: (1) D values are ranged from 32.7 to 0.00048 when the $\mathrm{HCl}$ acidities vary from 0.10 to $10.0 \mathrm{M}$, showing that polonium can well be extracted by $0.75 \mathrm{M}$ HDEHP in cyclohexane if the aqueous $\mathrm{HCl}$ acidities are $\leq 0.050 \mathrm{M}$ and it will not be extracted if $\geq 0.10 \mathrm{M} \mathrm{HCl}$; (2) $\mathrm{D}$ values are ranged from 47.1 to 0.0117 when the $\mathrm{HNO}_{3}$ acidities vary from 0.10 to $10.0 \mathrm{M}$, showing that polonium can be extractable by $0.75 \mathrm{M}$ HDEHP in cyclohexane and in a wide range acidity of $\leq 4 \mathrm{M} \mathrm{HNO}_{3}$. The different extraction behaviours of polonium in $0.75 \mathrm{M}$ HDEHP in cyclohexane and different acidities of $\mathrm{HCl}$ and $\mathrm{HNO}_{3}$ were found. The findings will be very helpful to improve the methods involving polonium decontamination for determination and separation of americium, curium as well as other radioelements in environmental soil, water and biological samples.
\end{abstract}

Keywords: Polonium, HDEHP, distribution coefficients.

\section{INTRODUCTION}

The element polonium $\left({ }^{210} \mathrm{Po}\right)$ was discovered by Marie Curie as the first element separated from pitchblende, and named after her home country, Poland [1, 2]. It has 25 known radioactive isotopes with mass numbers of 192-218, of which only the ${ }^{208} \mathrm{Po},{ }^{209} \mathrm{Po}$ and ${ }^{210} \mathrm{Po}$ have half-lives longer than days. Of these three, ${ }^{208} \mathrm{Po}$ and ${ }^{209} \mathrm{Po}$, being artificial isotopes are often be used as tracers in the analytical procedures for the determination of natural polonium isotope. However, it is ${ }^{210} \mathrm{Po}$, which lends itself well to industrial applications, particularly in static elimination and control, in neutron generation, and also as a heat source for satellite power supplies etc. Therefore, ${ }^{210} \mathrm{Po}$ is of the most interested polonium isotope from health physics and environmental impact viewpoints due to its radiation exposure.

Not like many other elements, studies on the physical properties and chemical behaviours of polonium is relatively difficult and less extent due to the facts that (1) there is no any stable isotope, and (2) a measurable mass of polonium compounds always contains very high specific radioactivity.

As the first evidence, it has long been said that polonium is volatile at high temperature $\left(<190^{\circ} \mathrm{C}\right)$. But which valence or compound of polonium is volatile is not well known. Some researchers [3] studied the volatility of polonium in soil by fusion method $\left(0.1 \mathrm{~g}\right.$ soil sample containing ${ }^{210} \mathrm{Po}$, mixed well with $2.0 \mathrm{~g}$ of $\mathrm{Na}_{2} \mathrm{CO}_{3}$ and $\mathrm{Na}_{2} \mathrm{O}_{2}$, and fused at $600{ }^{\circ} \mathrm{C}$ for different time periods of $10-120 \mathrm{~min}$ ). The obtained average volatility of polonium was $13.9 \pm 3.2 \%$, and the effect of the fusion time at $600{ }^{\circ} \mathrm{C}$ seems not significant. It means that most of the polonium remains not volatile. The observation of many experiments during polonium determination for some biological samples concluded that oxidationreduction process can cause a significant lost of polonium. It means that the volatility of polonium signifi-cantly depends

*Address correspondence to this author at the Agency for Environmental Protection and for Technical Services, Via V. Brancati 48, 00144 Roma, Italy; E-mail: jia@apat.it on its oxidation state. Therefore, question is raised: which oxidation state is responsible for major polonium volatility, valences of $+2,+4$, and probably +6 ?

As the second evidence, there is a lack of information about the chemical extraction behaviours of polonium with many popular used organic extractants [4], such as: Trioctyl-phosphine oxide (TOPO), di(2-ethyhexyl)phosphoric acid (HDEHP), tri-n-octylamine (TNOA), and tri-n-butyl phosphate (TBP) etc. Uranium and transuranium nuclides, such as ${ }^{238} \mathrm{U},{ }^{234} \mathrm{U},{ }^{235} \mathrm{U},{ }^{239+240} \mathrm{Pu},{ }^{238} \mathrm{Pu},{ }^{241} \mathrm{Am}$ etc, represent the highly radiotoxic and/or chemical toxic, long-lived and worldwidely dispersed $\alpha$-emitting radionuclides in the environment $[5,6]$. The activity concentration studies of these radionuclides in the environmental matrices can provide basic information on the contamination levels, sources, distributions, inventory estimation and ecological processes of the radionuclides in the environment. Due to the complexity of the matrices and the very low level of radioactivity in it, for most common determination techniques extensive sample preparation, separation and purification procedures are required to achieve accurate results [6-9]. TOPO, HDEHP, TNOA and TBP etc are very popularly used as extractants to separate actinides from the interfering elements in environmental samples. Interference of ${ }^{210}$ Po was observed and is also very critical in the determination of actinides in environmental samples due to the widespread occurrence of ${ }^{210} \mathrm{Po}$ as a natural radionuclide. For instance: (1) For the determination of uranium isotope composition in lichen and soil samples $[10,11],{ }^{232} \mathrm{U}\left[\mathrm{E}_{\alpha}=5.2635 \mathrm{MeV}(31 \%)\right.$ and 5.3203 $\mathrm{MeV}(69 \%)]$, which has a similar $\mathrm{E}_{\alpha}$ to ${ }^{210} \mathrm{Po}\left[\mathrm{E}_{\alpha}=5.304\right.$ $\mathrm{MeV}(100 \%)]$, is often used as a yield tracer. Due to the less effective separation of uranium from ${ }^{210} \mathrm{Po}$ in the Microthene-TOPO chromatographic column under the experimental conditions and the limited resolution of the $\alpha$-spectrometry (the best FWHM is about $20-30 \mathrm{keV}$ ), trace amounts of ${ }^{210} \mathrm{Po}$ can remain in the uranium fraction in the prepared disks of the samples. Owing to the interference of ${ }^{210} \mathrm{Po}$, yield correction from the ${ }^{232} \mathrm{U}$ counts can lead to inaccurate results and can make the uranium concentrations of the samples much 
lower than the real values [11]. (2) A similar interference of ${ }^{210}$ Po can also happen in americium analyses where Microthene-HDEHP chromatographic column was used, as the peaks of ${ }^{210} \mathrm{Po}$ and ${ }^{243} \mathrm{Am}\left(\mathrm{E}_{\alpha}=5.2766 \mathrm{MeV}\right)$ as an americium tracer are in the nearly same energy region and can not be resolved by $\alpha$-spectrometry [8]. (3) If compared with the ${ }^{210}$ Po concentration, plutonium nuclides only exist in extra-trace amount in environmental samples. The interference of ${ }^{210} \mathrm{Po}$ to the plutonium determinations by Microthene-TNOA chromatographic column can also be possible [6], because the peak of ${ }^{210} \mathrm{Po}$ appears just in the region between the doublet peak of ${ }^{239} \mathrm{Pu}\left[\mathrm{E}_{\alpha}=5.155 \mathrm{MeV} \quad(73.2 \%)\right],{ }^{240} \mathrm{Pu}$ $\left[\mathrm{E}_{\alpha}=5.1681 \mathrm{MeV}(73.5 \%)\right]$ and the peak of ${ }^{238} \mathrm{Pu}\left[\mathrm{E}_{\alpha}=5.465\right.$ $\mathrm{MeV}(28.3 \%)$ and $5.4992 \mathrm{MeV}$ (71.6\%)]. Good resolution sources for $\alpha$-spectrometry measurement are needed in order to reduce the interference of ${ }^{210} \mathrm{Po}$ for plutonium nuclide determination as less as possible.

Therefore, in order to improve the analytical techniques for actinides and some other interested elements it is certainly necessary and important to study the extraction behaviours of polonium in different organic phases (toluene, cyclohexane, xylene etc) of TOPO, HDEHP, TNOA and TBP etc, and aqueous phases $\left(\mathrm{HCl}, \mathrm{HNO}_{3}, \mathrm{H}_{2} \mathrm{SO}_{4}\right.$ etc). For this purpose, the distribution coefficients of polonium between $5 \%$ TOPO in toluene and aqueous hydrochloric and nitric acids have been studied previously [12]. The objective of this paper is to study the distribution coefficients of polonium between $0.75 \mathrm{M}$ HDEHP in cyclohexane and aqueous hydrochloric and nitric acids in detail. These data are needed to develop more accurate method for determination of americium and curium isotopes by $\alpha$-spectrometry, and are also helpful to improve the methods involving polonium separation for other element determination.

\section{MATERIALS AND METHOD}

\subsection{Apparatus and Reagents}

Polonium-209 as a yield tracer was determined by $\alpha$ spectrometry with a counting efficiency of $30.2 \%$ and a background of $\leq 6 \cdot 10^{-6} \mathrm{cps}$ in the appropriate energy region.

A Perspex disk holder for polonium deposition was specially designed to fit $100-250 \mathrm{ml}$ beakers [13]. Silver foil of $0.15 \mathrm{~mm}$ thickness was used for ${ }^{210} \mathrm{Po}$ spontaneous deposition and it was cut into disks of $23 \mathrm{~mm}$ in diameter.

Polonium-209 standard solution $\left(0.0542 \mathrm{~Bq} \mathrm{ml}^{-1}\right.$ in $2 \mathrm{M}$ $\mathrm{HCl}$ ) and di(2-ethyhexyl)phosphoric acid (HDEHP, > 97\%) were supplied by Amersham (G. B.) and Merck (Germany) respectively. All other reagents were analytical grade.

\subsection{Method}

An aliquot of $0.50 \mathrm{ml}{ }^{209}$ Po standard solution $(0.0271 \mathrm{~Bq})$ was added to a $100 \mathrm{ml}$ beaker, which was slowly heated on a hot-plate $\left(200{ }^{\circ} \mathrm{C}\right)$ until incipient dryness. Then the ${ }^{209} \mathrm{Po}$ in the beaker was transferred into a $10 \mathrm{ml}$ graduated centrifuge tube with $3 \mathrm{ml}$ of $\mathrm{HCl}$ or $\mathrm{HNO}_{3}$ solution at different concentrations $(0.010,0.050,0.10,0.50,1.0,2.0,4.0,6.0$, 8.0, and $10.0 \mathrm{M}$ ). $3.0 \mathrm{ml}$ of $0.75 \mathrm{M}$ HDEHP in cyclohexane were added to the tube and shaking was carried out at room temperature $\left(22 \pm 2{ }^{\circ} \mathrm{C}\right)$ for $5 \mathrm{~min}$. After centrifuging at 4000 rpm for $5 \mathrm{~min}$, the aqueous phase (extracting solution) was taken out to a $150 \mathrm{ml}$ beaker. The organic phase was diluted to $4.5 \mathrm{ml}$ with benzene and washed with $4.5 \mathrm{ml}$ of distilled $\mathrm{ml}$ with benzene and washed with $4.5 \mathrm{ml}$ of distilled water to lower the acidity of the solution. Finally, the polonium in the organic phase was back-extracted twice with same volume of $0.025 \mathrm{M}\left(\mathrm{NH}_{4}\right)_{2} \mathrm{C}_{2} \mathrm{O}_{4}$ solution. All the washing and backextracting solutions were combined in another $150 \mathrm{ml}$ beaker. In order to destroy the residue organic matters, the extracting and back-extracting solutions were evaporated to dryness. $1 \mathrm{ml}$ of concentrated $\mathrm{HCl}$ was added and the residue was boiled at $100{ }^{\circ} \mathrm{C}$ for some minutes with addition some drops of $30 \% \mathrm{H}_{2} \mathrm{O}_{2}$. After cooling, the $\mathrm{pH}$ of the solution was adjusted to 1.5 with 1:5 (v/v) ammonia. The solution was diluted to $50 \mathrm{ml}$, heated and stirred on a hot-plate magnetic stirrer. A Perspex holder with a silver disk was placed on the beaker and the silver disk was immersed into the solution. Any air bubbles trapped beneath the disk were removed by manipulation of the stirrer bar. The polonium deposition was continued for 5-6 h at $85-90{ }^{\circ} \mathrm{C}$, then the disk was removed, washed with distilled water and acetone, dried and assayed by $\alpha$-spectrometry. For detailed analytical procedure, please refer to literature [14].

\subsection{Distribution Coefficients}

The distribution coefficient (D) was calculated as follows:

$$
D=\frac{A o V w}{A w V o}
$$

Where, $A_{o}$ and $A_{w}$ are the ${ }^{209}$ Po activities in the organic and aquatic solutions; $V_{o}$ and $V_{w}$ are the volumes of the organic and aquatic solutions.

\section{RESULTS AND DISCUSSION}

It was reported that some polonium compounds are volatile, possibly in its pure and chloride forms [2]. Therefore, the studies on the polonium extraction by HDEHP in cyclohexane and acidified aqueous phases are not easily achievable due to its volatility. In this work polonium yield determination is obliged in order to evaluate the correctness of the obtained distribution coefficients. The yields are defined as the ratios of the total polonium activity obtained from both organic and aqueous phases to that added. Higher yields with less variation are required to derive reliable $\mathrm{D}$ values. The most important measure was to evaporate and deposit polonium under the nearly same condition. The standard deviations given in Table $\mathbf{1}$ for individual data are $1 \sigma$, which is obtained from 2-4 times tests.

As shown in Table 1, at each condition the polonium yield $(\geq 50 \%)$ is relatively constant. Therefore, the obtained $\mathrm{D}$ values of polonium are reasonable in both hydrochloric and nitric acids. But an increasing tendency of the yields with the increasing of the acidities in both cases was observed. Low yields, meaning loss of polonium, are not due to its volatility, but to the fact that the polonium deposited on wall of the beaker during the evaporation process needed for the acid medium change can more effectively be washed by the higher acidity.

The distribution coefficients of polonium between 0.75 $\mathrm{M}$ HDEHP in cyclohexane and aqueous $\mathrm{HCl}$ at different acidities are shown in Fig. (1). It is indicated that: (1) the D values of polonium are decreasing with the increasing of 
Table 1. Yields and Distribution Coefficients (Mean $\pm 1 \sigma)$ of Polonium Between 0.75 M HDEHP in Cyclohexane and Aqueous Hydrochloric and Nitric Acids

\begin{tabular}{|c|c|c|c|c|}
\hline \multirow{2}{*}{ Acidity, M } & \multicolumn{2}{|c|}{ HCl } & \multicolumn{2}{c|}{ HNO $^{2}$} \\
\cline { 2 - 5 } & Po yield, \% & Po yield, \% & D \\
\hline 0.010 & $53.7 \pm 0.9$ & $32.7 \pm 7.6$ & $43.9 \pm 0.6$ & $10.3 \pm 1.3$ \\
\hline 0.050 & $57.5 \pm 18.8$ & $5.16 \pm 2.70$ & $54.1 \pm 0.1$ & $4.74 \pm 0.18$ \\
\hline 0.10 & $88.8 \pm 10.9$ & $0.0077 \pm 0.0002$ & $50.4 \pm 5.3$ & $2.31 \pm 0.05$ \\
\hline 0.50 & $97.1 \pm 4.0$ & $0.00048 \pm 0.00006$ & $59.0 \pm 5.0$ & $1.12 \pm 0.14$ \\
\hline 1.0 & $83.6 \pm 3.8$ & $0.00259 \pm 0.00142$ & $68.4 \pm 0.4$ & $0.475 \pm 0.041$ \\
\hline 2.0 & $98.7 \pm 3.4$ & $0.00119 \pm 0.00070$ & $74.0 \pm 2.6$ & $0.0842 \pm 0.0066$ \\
\hline 4.0 & $91.5 \pm 2.1$ & $0.00056 \pm 0.0005$ & $81.8 \pm 0.8$ & $0.0222 \pm 0.0090$ \\
\hline 6.0 & $97.7 \pm 1.5$ & $0.00225 \pm 0.00165$ & $94.9 \pm 0.5$ & $0.0133 \pm 0.0039$ \\
\hline 8.0 & $96.9 \pm 1.1$ & $0.00337 \pm 0.00062$ & $97.2 \pm 2.1$ & $0.0117 \pm 0.0057$ \\
\hline 10.0 & $86.5 \pm 7.5$ & $0.00219 \pm 0.00234$ & $98.2 \pm 0.1$ & \\
\hline
\end{tabular}

*which are obtained from 2-4 times tests.

$\mathrm{HCl}$ acidities; (2) $\geq 83.3 \%$ of polonium can be extracted by $0.75 \mathrm{M}$ HDEHP in cyclohexane when aqueous $\mathrm{HCl}$ acidities are $\leq 0.050 \mathrm{M}(\mathrm{D} \geq 5.16)$; and (3) nearly all the polonium ( $\geq$ 99\%) remains in the aqueous phase if the $\mathrm{HCl}$ acidities are in the range of $0.10-10 \mathrm{M}$, and it means that polonium is not extractable $(\mathrm{D} \leq 0.0077)$ when the $\mathrm{HCl}$ acidities are $\geq 0.10$ M.

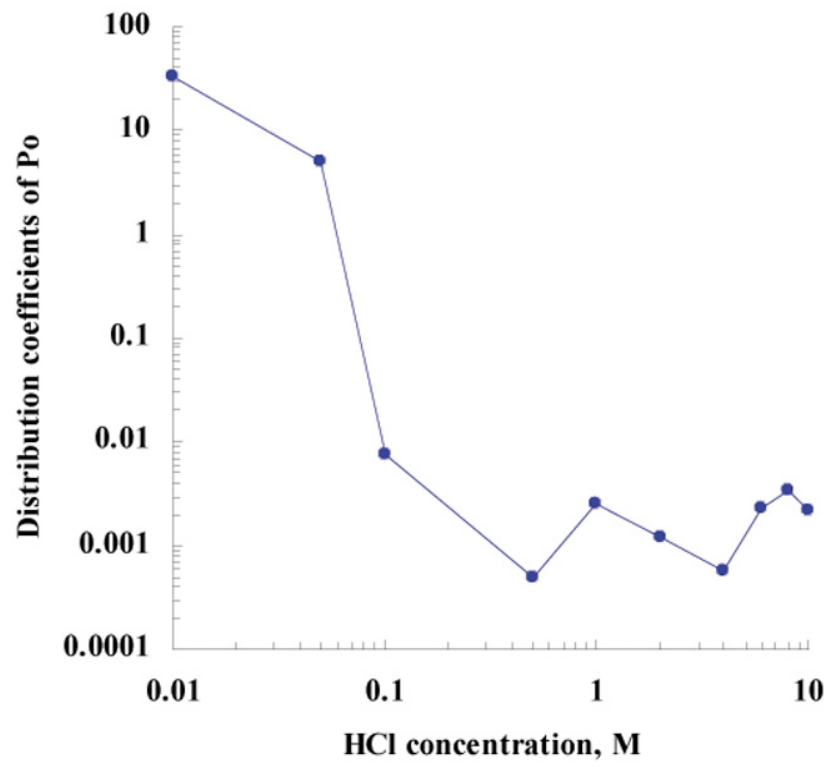

Fig. (1). Distribution coefficients of polonium between $0.75 \mathrm{M}$ HDEHP in cyclohexane and aqueous hydrochloric acid.

The distribution coefficients of polonium between 0.75 $\mathrm{M}$ HDEHP in cyclohexane and aqueous $\mathrm{HNO}_{3}$ at different acidity are shown in Fig. (2). It is indicated that: (1) the D values of polonium are also decreasing with the increasing of $\mathrm{HNO}_{3}$ acidities from 0.010 to $10.0 \mathrm{M}$, but the decreasing tendency is less than in the $\mathrm{HCl}$ medium; (2) an observable amount of polonium (7.8\%) can still be extracted by $0.75 \mathrm{M}$
HDEHP in cyclohexane and in aqueous solution of $4 \mathrm{M}$ $\mathrm{HNO}_{3}(\mathrm{D}=0.084)$; and (3) polonium can be considered as not extractable in the aqueous acidities of $\geq 8 \mathrm{M} \mathrm{HNO}_{3}$ (D< $0.0133)$.

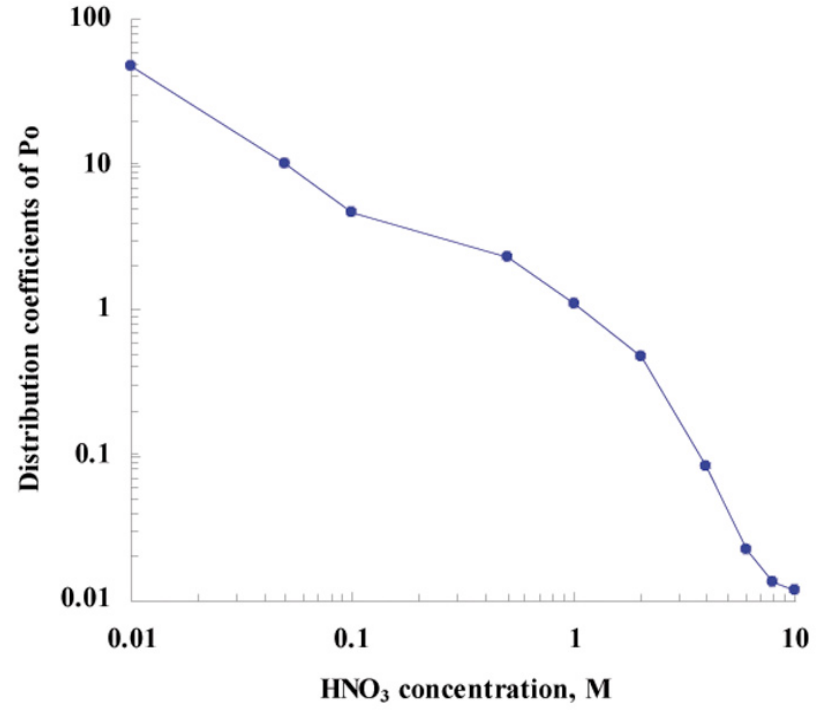

Fig. (2). Distribution coefficients of polonium between $0.75 \mathrm{M}$ HDEHP in cyclohexane and aqueous nitric acid.

The Figs. (1 and 2) clearly show the different extraction behaviours of polonium in $0.75 \mathrm{M}$ HDEHP in cyclohexane and in different acidities of $\mathrm{HCl}$ and $\mathrm{HNO}_{3}$. The findings are very helpful to improve the method for determination of the low-level activity concentrations of americium and curium in environmental soil, water and biological samples. In the most routine procedures for americium and curium separation, $0.10 \mathrm{M} \mathrm{HNO}_{3}$ was often selected as the washing solution for elimination of polonium. In fact, at this condition the $\mathrm{D}_{\mathrm{HNO}}$ value is 4.74 , which is much higher than the $\mathrm{D}_{\mathrm{HCl}}$ (0.0077). Therefore, to effectively eliminate polonium from americium and curium fraction in the liquid-liquid extraction 
and/or column extraction chromatography of HDEHP, 0.10 $\mathrm{M} \mathrm{HCl}$ should be used as the washing solution instead of $0.10 \mathrm{M} \mathrm{HNO}_{3}$.

\section{CONCLUSION}

The obtained results indicate that: (1) D values are ranged from 32.7 to 0.00048 when the $\mathrm{HCl}$ acidities vary from 0.10 to $10.0 \mathrm{M}$, showing that polonium can well be extracted by $0.75 \mathrm{M}$ HDEHP in cyclohexane if the aqueous $\mathrm{HCl}$ acidities are $\leq 0.050 \mathrm{M}$ and it will not be extracted if $\geq$ $0.10 \mathrm{M} \mathrm{HCl}$; (2) $\mathrm{D}$ values are ranged from 47.1 to 0.0117 when the $\mathrm{HNO}_{3}$ acidities vary from 0.10 to $10.0 \mathrm{M}$, showing that polonium can be extractable by $0.75 \mathrm{M}$ HDEHP in cyclohexane in a wide range acidity of $\leq 4 \mathrm{M} \mathrm{HNO}_{3}$. The different extraction behaviours of polonium in $0.75 \mathrm{M}$ HDEHP in cyclohexane and in different acidities of $\mathrm{HCl}$ and $\mathrm{HNO}_{3}$ were found. The findings will be very helpful to improve the methods of liquid-liquid extraction and/or column extraction chromatography of HDEHP involving polonium decontamination, such as for determination and separation of americium, curium as well other radioelements in environmental soil, water and biological samples.

\section{REFERENCES}

[1] Matthews, M.K.; Kim, C-K.; Paul, M. Appl. Radiat. Isotopes, 2007, 65(3), 267.
Partington, J. R. (Ed.) General and Inorganic Chemistry, Fourth edition; Macmillan London, Melbourne, Toronto ST Martiu's press: New York, 1996, p. 737a.

[3] Jia, G.; Torri, G. Appl. Radiat. Isotopes, 2007, 65(1), 1.

[4] Braun, T.; Ghersini, G. (Eds.) Extraction chromatography, Elsevier: Amsterdan, 1975, p. 89.

[5] Allain, P.; Berre, S.; Premel-Cabic, A.; Mauras, Y. Anal. Chim. Acta, 1991, 251, 183.

[6] Jia, G.; Testa, C.; Desideri, D.; Guerra, F.; Meli, M.A.; Roselli, C.; Belli, M. Health Phys., 1999, 77(1), 52.

[7] Jia, G.; Testa, C.; Desideri, D.; Meli, M.A. J. Radioanal. Nucl. Chem., 1989, 133, 227.

[8] Jia, G.; Desideri, D.; Guerra, F.; Meli, M.A.; Testa, C. J. Radioanal. Nucl. Chem., 1997, $220(1), 15$.

[9] Jia, G.; Testa, C.; Desideri, D.; Guerra, F.; Roselli, C. J. Radioanal. Nucl. Chem., 1998, 230(1-2), 21.

[10] Jia, G.; Belli, M.; Sansone, U.; Rosamilia, S.; Ocone, R.; Gaudino, S. J. Radioanal. Nucl. Chem., 2002, 253(3), 395.

[11] Jia, G.; Torri, G.; Innocenzi, P. J. Radioanal. Nucl. Chem., 2004 262(2), 433.

[12] Jia, G.; Torri, G.; Petruzzi, M. Appl. Radiat. Isotopes, 2004, 61(23), 279.

[13] Jia, G.; Belli, M.; Blasi, M.; Marchetti, A.; Rosamilia, S.; Sansone, U. Appl. Radiat. Isotopes, 2000, 53, 115 .

[14] Jia, G.; Belli, M.; Blasi, M.; Marchetti, A.; Rosamilia, S.; Sansone, U. J. Radioanal. Nucl. Chem., 2001, 247(3), 491. 